\title{
CRIMES DE PESCA NO PANTANAL: DE QUEM É A COMPETÊNCIA PARA LEGISLAR?
}

\author{
Fabio Marques Barbosa ${ }^{1}$ \\ Lamartine Ribeiró \\ José Manfrop
}

\section{RESUMO}

Com abordagem fundamentada nos preceitos Constitucionais, o presente trabalho, influência da experiência profissional do autor, que atuou como Policial Militar Ambiental no município de Corumbá, em Mato Grosso do Sul, teve a intenção de investigar, como principal objeto de pesquisa, a competência da defesa do bioma Pantanal. Foi constatado, durante os levantamentos iniciais, que alguns princípios constitucionais ambientais não estão sendo obedecidos, como por exemplo, o princípio da predominância da norma mais benéfica ao meio ambiente. A pesquisa, porém, não proporcionou uma resposta precisa à indagação inicial, já que não foram encontrados posicionamentos doutrinários ou jurisprudenciais sobre a matéria. Dessa forma, fez-se necessária a construção de um raciocínio baseado na hermenêutica constitucional, com referência às atuais concepções sobre a repartição de competências em matéria ambiental, alcançando, assim, uma possibilidade de resposta ao questionamento.

Palavras-Chave: Conflito de Competência. Crimes de pesca. Normas Penais em Branco. Pantanal.

\section{INTRODUÇÃO}

O Pantanal sul-mato-grossense é a maior área alagável do mundo. É considerado um grande delta interno e um grandioso santuário ecológico, onde se acumulam as águas da bacia do Rio Paraguai, originando uma enorme diversidade de fauna e flora. O turismo contemplativo e a prática da pesca trazem, todos os anos, milhares de pessoas do Brasil e do mundo. No meio desse santuário, assentase Corumbá, que segundo a língua tupi-guarani (curupah), significa "qugar distante". Banhado pelo rio Paraguai e por alguns afluentes do Estado de Mato Grosso do Sul, o município é um atrativo turístico, sendo a exploração da pesca um fator importante para a sua economia.

A fiscalização das águas pantaneiras, predominantemente de interesse da União, é realizada pelo Instituto Brasileiro do Meio Ambiente e dos Recursos Naturais Renováveis (IBAMA) e pela Polícia Militar Ambiental do Estado de Mato Grosso do Sul, através de convênio.

Os enquadramentos legais diante de um ato ilícito de pesca são baseados nas legislações federal e estadual. De acordo com a gravidade da infração, são imputadas ao autor da ilicitude sanções administrativas ou penais: estas seguem a tipificação constante na Lei $n^{\circ}$ 9.605/98 (Lei dos Crimes Ambientais) e aquelas, além do Decreto $n^{\circ} 6.514 / 08$, as legislações estaduais. Todavia, para a maioria dos delitos ambientais, a tipificação constante na Lei $n^{0} 9.605 / 98$ necessita da complementação 
de outras normas federais, estaduais ou municipais, dependendo da predominância da competência constitucional. Essas normas complementadas são denominadas normas penais em branco.

A questão em estudo no presente artigo é, então, analisar as normas em vigor no tocante aos crimes de pesca cometidos no Pantanal, para, ao final, tentar apontar a quem compete legislar sobre a matéria, observando se os princípios norteadores do direito ambiental estão sendo respeitados. Para isso, serão apresentados tópicos sobre os fundamentos da lei de pesca, a competência legislativa em matéria ambiental, as normas penais em branco, o poder de polícia do estado e a legislação pesqueira vigente.

Embora esta seja uma discussão com pouca jurisprudência e escassos posicionamentos doutrinários, ela é bastante relevante para o universo acadêmico, e para a população regional, sobretudo devido à iminente reforma na legislação pesqueira do Estado, o que certamente, importará na transformação das vidas daqueles que dependem da exploração desses recursos naturais.

\section{FUNDAMENTOS DA LEI DE PESCA}

Para que seja dada efetividade à proteção da natureza, o legislador brasileiro utiliza-se, além da tutela constitucional, da tutela civil, administrativa e penal.

A Constituição Federal, em seu art. $225, \S 3^{\circ}$, estabelece que as condutas e atividades consideradas lesivas ao meio ambiente sujeitarão aos infratores, pessoas físicas ou jurídicas, sanções penais e administrativas, independente da obrigação de reparar os danos causados.

Tratando-se de crime de pesca, foram sancionados três artigos da Lei $\mathbf{n}^{\circ}$ 9.605/98 (Lei dos crimes ambientais), que embora relevantes, têm sua eficácia contestada, devido ao grande índice de reincidência. Tais dispositivos, doravante analisados, protegem de forma expressa a fauna ictiológica ${ }^{4}$ e tipificam condutas que caracterizam a prática da pesca predatória, prevendo penas restritivas de liberdade ou de direitos, cumuladas ou não com multas.

É preciso evidenciar que, embora exista previsão legal para a aplicação de penas restritivas de liberdade, cumuladas ou não com a pecuniária, as penas aplicadas no Direito Penal Ambiental, na prática, acabam sendo restritivas de direitos, em observância ao disposto no art. $7^{\circ}$, I, da Lei $n^{\circ} 9.605 / 98$, que prevê a substituição quando aquelas não ultrapassarem quatro anos. Como são poucos os casos em que a pena alcança quatro anos de detenção e, normalmente, no Brasil, as penas são aplicadas no mínimo legal, dificilmente, alguém terá sua liberdade cerceada por uma ilegalidade ambiental.

Ao lado dos dispositivos até aqui mencionados, existem ainda outros, na esfera Estadual, que suplementam a legislação Federal e regulamentam os procedimentos administrativos, como o estabelecimento de cota de pescado, o tamanho mínimo das espécies para a captura, o período de defeso ${ }^{5}$, etc., que devem ser aplicados observando normas diretivas peculiares ao Direito Ambiental. 


\section{TIPO PENAL ABERTO}

Em observância aos princípios constitucionais da reserva legal ou do contraditório, é consignado ao agente o direito de se defender. Por esse motivo, em tese, as normas penais devem descrever completamente todas as características do fato típico. Todavia, as condutas lesivas ao meio ambiente, que possuem formas múltiplas e mudam freqüentemente, nem sempre permitem uma descrição direta e objetiva, como ocorre nos delitos comuns.

Para Heleno Cláudio Fragoso (1958), alguns tipos penais não descrevem de forma expressa ou completa a transgressão do agente delituoso, dependendo da violação de normas especiais que o tipo pressupõe. Dessa maneira, a ilicitude deve ser estabelecida pelo juiz, que verificará se houve ou não a transgressão das normas que a incriminação pressupõe.

Por esse e por outros motivos, temas referentes aos tipos penais ambientais são amplamente discutidos pela doutrina. Por serem, algumas vezes, demasiadamente abertos, recorre-se, em muitos casos, às normas penais em branco.

\section{NORMAS PENAIS EM BRANCO}

É através de ato administrativo emanado de órgãos ambientais integrantes do SISNAMA ${ }^{6}$ que melhor se protegerá o meio ambiente. Estes órgãos definem os locais, períodos e condições em que os recursos naturais devem ser explorados de forma sustentável.

Como anteriormente mencionado, em determinados momentos, a lei faz remissões da norma a outros dispositivos, para que as complementem, devido à sua complexidade técnica.

Para Fernando Capez (2003), tais normas, denominadas normas penais em branco, são dispositivos nos quais o preceito secundário (cominação da pena) está completo, permanecendo indeterminado o seu conteúdo. 'Trata-se, portanto, de uma norma cuja descrição da conduta está incompleta, necessitando de complementação por outra disposição legal ou regulamentar" (p. 32). 0 autor classifica-as em "sentido lato ou homogêneas; sentido estrito ou heterogêneas; norma penal em branco ao avesso" (p. 32).

Segundo Arthur Migliari Junior (2003), normas penais em branco são aquelas que não possuem conteúdo incriminador por si só, exigindo complementação por outra norma jurídica, como a edição de uma lei, um decreto, um regulamento, uma portaria de determinado Departamento do Estado, etc., a fim de que possam ser aplicadas ao fato concreto.

Analisando especificamente os artigos 34 e 35 da Lei $n^{\circ}$ 9.605/98, observa-se que o tipo penal é remetido a outros dispositivos, que regulamentarão tais condutas. A expressão "autoridade competente", que regulamentará a pesca, por exemplo, se refere ao IBAMA ou ao órgão estadual que desempenhe funções delegadas. 
Assim, essa complementação não ofende o princípio da reserva legal. Entretanto, um óbice que, eventualmente, poderia ser suscitado contra essa afirmação, seria a disposição estampada no art. 22, inciso I, da Carta Constitucional. Conforme esse artigo, compete privativamente à União legislar sobre direito penal. Nessa esteira, atos emanados de autoridade estadual não deveriam integrar os preceitos incriminadores de normas penais em branco, ou amparar juízo valorativo referente a elementos normativos, sob pena de inconstitucionalidade formal. Porém, os mencionados atos estaduais ou municipais não inovam o direito penal e nem criam novas condutas típicas. São, na verdade, uma disposição meramente complementar.

\section{COMPETÊNCIA EM MATÉRIA AMBIENTAL}

A Constituição de 1988 adotou como forma de Estado o federalismo ${ }^{7}$, determinando a capital federal em Brasília. A organização político-administrativa compreende a União, os Estados, o Distrito Federal e os Municípios, todos autônomos nos termos da Constituição Federal. Essas entidades federativas se manifestam sobre a mesma população e sobre o mesmo território, e, por esse motivo, a repartição de competências entre os entes governamentais constitui um dos núcleos fundamentais do Estado Federal Brasileiro e um dos temas mais conflituosos em matéria ambiental.

José Afonso da Silva (2007), considera que a "competência é a faculdade juridicamente atribuída à uma entidade ou a um órgão ou agente do Poder Público para emitir decisões. [...] são as diversas modalidades de poder de que se servem os órgãos ou entidades estatais para realizar suas funções" (p. 71). A autonomia federativa, segundo o autor, "assenta-se em dois elementos básicos: a existência de órgãos governamentais próprios e a posse de competências exclusivas”. (p. 72)

De acordo com o magistério de Alexandre de Moraes (2004), o princípio geral que norteia a repartição de competências é o da predominância do interesse. Ele explica:

Pelo principio da predominância do interesse, à União caberá aquelas matérias e questões de predominância do interesse geral ao passo que aos Estados referem-se as matérias de predominante interesse regional, e aos Municípios concernem os assuntos de interesse local. Em relação ao Distrito Federal, por expressa disposição constitucional (CF, art. 32, $\left.\S 1^{\circ}\right)$, acumulam-se, em regra, as competências estaduais e municipais, com a exceção prevista no art. $22^{8}$, XVII, da Constituição. (p. 290)

Adotando o referido princípio, o legislador constituinte estabeleceu quatro pontos básicos no regramento constitucional para a divisão de competências administrativas e legislativas (MORAES, 2004):

1. Reserva de campos específicos de competência administrativa e legislativa:

União - Poderes enumerados (CF, arts, 21 e 22);

Estados - Poderes remanescentes (CF, art. 25, § $\left.1^{\circ}\right)$;

Município - Poderes enumerados (CF, art. 30);

Distrito Federal - Estados + Municípios (CF, art. 32, § $\left.1^{\circ}\right)$ 
2. Possibilidade de delegação (CF, art. 22, parágrafo único) - Lei complementar federal poderá autorizar os Estados a legislar sobre questões específicas das matérias de competência privativa da União.

3. Áreas comuns de autuação administrativa paralela (CF, art. 23).

4. Áreas de autuação legislativa concorrente (CF, art. 24). (p. 291)

Em relação à classificação das competências, FERREIRA (2007), posiciona-se da seguinte forma:

I - Quanto à natureza:

a) executivas: reserva a determinada esfera do poder 0 direito de estabelecer e executar diretrizes, estratégias e políticas relacionadas ao meio ambiente;

b) administrativas: traz o sentido de implementação e fiscalização, ou seja, remete ao exercício do poder de polícia pelas entidades federativas com o propósito de proteger e presenvar o meio ambiente;

c) legislativa refere-se à capacidade outorgada a um ente da Federação para legislar sobre questões referentes à temática ambiental.

II - Quanto à extensão:

a) exclusivas: exclui os demais entes federativos do seu exercício;

b) privativa: embora seja também específica de determinado nível de governo, admite delegação ou suplementariedade;

c) comum: também denominada cumulativa ou paralela, é exercida de forma igualitária por todos os entes que compõem a Federação;

d) concorrente: prevê a possibilidade de disposição sobre determinada matéria por mais de um ente federativo, havendo entretanto, uma primazia por parte da União quanto a fixação de nomas gerais;

e) suplementar: indica a possibilidade de edição de normas que pormenorizem normas gerais existentes ou supram a sua ausência ou omissão. (p. 204-206)

Posto isso, pode-se dizer que compete à União a elaboração de normas gerais, restando aos demais entes políticos a especificação das condutas, observando-se a realidade local.

\section{CONFLITOS DE COMPETÊNCIAS}

A distância do poder central e uma possível disputa pelo poder entre os órgãos ambientais, muitas vezes, podem gerar dificuldades na aplicação das normas em casos concretos. Essas dificuldades têm influência direta no que se refere à repartição de competências. São invocados, então, os princípios constitucionais, a doutrina e a jurisprudência, para estabelecer a predominância das normas.

Para Fernando Capez (2003), há conflito quando duas ou mais normas pretendem regulamentar, aparentemente, o mesmo fato. No entanto, apenas uma delas acaba sendo aplicada. Para o autor, o caso fica configurado com a presença dos seguintes elementos:
a) unidade do fato (há somente uma infração penal);
b) pluralidade de normas (duas ou mais normas pretendendo regulá-lo);
c) aparente aplicação de todas as normas à espécie ( a incidência de todas é apenas aparente);
d) efetiva aplicação de apenas uma delas (somente uma é aplicável, razão pela qual o conflito é aparente). (p. 67)

Freitas (2007) estabelece alguns posicionamentos nas situações mais comuns: 
Em princípio: a) quando a competência for privativa da União, a eventual fiscalização de órgão estadual ou municipal com base na competência comum de proteção ao meio ambiente não retira a prevalência federal; b) quando a competência for comum (por exemplo, presenvação de florestas), deve ser verificada a existência ou não de interesse nacional, regional ou local e, a partir daí, definir a competência material (por exemplo, a devastação de grandes proporções na Serra do Mar configura interesse federal, em face do contido no art. 225, $\S 4^{\circ}$, da Constituição Federal); c) quando a competência for do Estado, por não ser a matéria privativa da União ou do Município (residual), a ele cabe a prática dos atos administrativos pertinentes, como fiscalizar ou impor sanções (por exemplo, controle da pesca em rio municipal); d) no mar territorial a fiscalização cabe à Capitania dos Portos, do Ministério da Marinha; e) cabe ao Município atuar apenas em caráter supletivo quando a matéria for do interesse comum e houver ação federal ou estadual; f) cabe ao Município atuar privativamente quando a matéria for do interesse exclusivo local (por exemplo, poda de árvores nas vias públicas). (p. 80)

FERREIRA (2007), assinalando também normas conflitantes, aponta três possibilidades de análise:

a) pode ocorrer que, mesmo observando os seus campos de atuação, União e Estados legislem de forma conflitante. Nesse caso, entende-se que deverá predominar a regra mais restritiva, uma vez que se busca a satisfação de um interesse público; b) uma segunda possibilidade consiste na inobsenância dos limites constitucionais impostos ao exercício da competência concorrente. A invasão do campo de atuação alheio implica a inconstitucionalidade da lei, seja ela federal, seja ela estadual; c) finalmente, pode ainda o conflito entre leis resultar da impossibilidade de definir precisamente o que são normas gerais e normas especiais. Tais conflitos devem ser solucionados tendo por base o princípio in dúbio pro natura, devendo prevalecer a norma que melhor defenda o direito fundamental tutelado, ou seja, o meio ambiente. (p. 215).

Observa-se, segundo a autora, que, sendo a norma mais restritiva ao homem, ela será mais benéfica ao meio ambiente, devendo assim, ter prevalência diante da norma mais permissiva.

\section{O PANTANAL MATO-GROSSENSE E O CONFLITO DE COMPETÊNCIAS}

A região do Pantanal ocupa uma área aproximada de $250 \mathrm{mil} \mathrm{km}^{2}$, formando a maior planície inundável do planeta, localizada em território brasileiro, argentino, boliviano e paraguaio. Considerado um patrimônio nacional e constituído por rios de interesse da União e dos estados de Mato Grosso e Mato Grosso do Sul, o Pantanal ocupa uma área de $138 \mathrm{mil} \mathrm{km}$, distribuído entre estes dois estados.

O fato de constituir um patrimônio nacional deixa explícito o interesse da União em tutelar tal ecossistema. Porém, o Pantanal, como outros patrimônios nacionais, ainda não possuem uma legislação própria para a sua proteção.

0 art. 225, da Constituição Federal, impõe ao Poder Público o dever de defender e preservar o meio ambiente, tomando todas as medidas para assegurar a efetividade da tutela ambiental. Cada ente federado deverá atuar respeitando os limites de sua competência. Como evidenciado, há casos excepcionais, em que a 
competência administrativa comum poderá ser exercida por um ente distinto daquele que editou a norma.

A Carta Magna traz dispositivos que enumeram os bens pertencentes aos entes federados, distribuídos da seguinte forma:

Art. 20. São bens da União:

[...]

III - os lagos, rios e quaisquer correntes de água em terrenos de seu domínio, ou que banhem mais de um Estado, sivam de limites com outros países, ou se estendam a território estrangeiro ou dele provenham, bem como os terrenos marginais e as praias fluviais;

[...]

Art. 26. Incluem-se entre os bens dos Estados:

I - as águas superficiais ou subterrâneas, fluentes, emergentes e em depósito, ressalvadas, neste caso, na forma da lei, as decorrentes de obras da União;

[...]

Art. 225. Todos têm direito ao meio ambiente ecologicamente equilibrado, bem de uso comum do povo e essencial à sadia qualidade de vida, impondo-se ao Poder Público e à coletividade o dever de defendê-lo e preservá-lo para as presentes e futuras gerações.

[...]

$\S 4^{\circ}$. A Floresta Amazônica brasileira, a Mata Atlântica, a Serra do Mar, o Pantanal Mato-Grossense e a Zona Costeira são patrimônio nacional, e sua utilização far-se-á, na forma da lei, dentro de condições que assegurem a preservação do meio ambiente, inclusive quanto ao uso dos recursos naturais.

$[\cdots]$

Dessa forma, é notória a constatação de que o Pantanal é um patrimônio nacional, permanecendo, assim, o interesse da União em sua tutela, embora seja permitido aos Estados de Mato Grosso e Mato Grosso do Sul suplementar a legislação federal.

\section{LEGISLAÇÃO VIGENTE}

Como registrado, além da Lei $n^{0}$ 9.605/98 e demais normas federais, existem, no Estado de Mato Grosso do Sul, outros dispositivos que suplementam a legislação federal, seja para regulamentar a pesca no Estado ou para atribuir sanções administrativas pela prática da pesca ilícita.

O Decreto $n^{\circ} 5.583$, de 16 de novembro de 2005, autoriza o IBAMA a estabelecer normas para a gestão do uso sustentável dos recursos pesqueiros. 0 art. 93, da Constituição do Estado de Mato Grosso do Sul, atribui a mesma competência à SEMAC ${ }^{9}$, na esfera estadual. Vinculada a essa Secretaria, foi instituído, no ano de 2007, pelo Decreto $n^{\circ} 12.231 / 2007$, o IMASUL ${ }^{10}$, com a finalidade de coordenar e executar a política de meio ambiente em todo o território do Estado de Mato Grosso do Sul e fazer cumprir as legislações federal e estadual sobre essa atividade.

Para praticar a pesca no Estado de Mato Grosso do Sul, além dos dispositivos já comentados, o pescador, residente ou não no estado, deverá se atentar para as seguintes normas: 
- $\quad$ Decreto-lei n 221, de 1967, Código de Pesca: dispõe sobre a proteção e estímulos à pesca e dá outras providências.

- Decreto $n^{\circ}$ 6.514/2008: dispõe sobre a especificação das sanções aplicáveis às condutas e atividades lesivas ao meio ambiente.

- Lei Estadual no 3.329, de 19 de Dezembro de 2006: estabelece normas para a exploração de recursos pesqueiros no Estado de Mato Grosso do Sul.

- $\quad$ Decreto Estadual n 11.724, de 05 de novembro de 2004.

- As portarias do IBAMA, que fixam anualmente o período de proibição da pesca e dão outras providências para todo território nacional, como cota e tamanho mínimo para a captura das espécies, local e petrechos permitidos para a pesca, etc.

- As resoluções da SEMAC, que fixam anualmente o período de proibição da pesca e dão outras providências para todo território do Estado de Mato Grosso do Sul, como cota e tamanho mínimo para a captura, locais e períodos permitidos para a pesca, etc.

Devido à complexidade das normas e a necessidade de complementação destas, se nota, constantemente, alguns conflitos entre as legislações federal e estadual, principalmente no tocante à regulamentação das cotas, petrechos permitidos e tamanho mínimo para a captura.

Impende destacar que a cota de captura permitida aos pescadores amadores no Estado de Mato Grosso do Sul, até julho de 1995, foi equivalente à cota estabelecida pela legislação federal, que era de $30 \mathrm{~kg}$ e mais um exemplar. $O$ Estado passou a adotar, a partir daí, cotas mais restritivas, reduzindo-as progressivamente. Tal procedimento fez com que o turismo de pesca, segundo a Embrapa ${ }^{11}$, sofresse uma acentuada evasão. Com isso, a partir de 2004, a cota estadual igualou-se novamente à federal - $10 \mathrm{~kg}$ e mais um exemplar (Portaria IBAMA $\mathrm{n}^{\circ} 30$, de 23 de maio de 2003). No ano de 2006, a cota foi estabelecida com dois exemplares (um de couro e um de escama) voltando a ser equiparada no ano seguinte.

Para demonstrar o conflito das normas regulamentadoras federal e estadual, duas tabelas são apresentadas abaixo. Em pleno vigor, esta portaria e decreto fixam o tamanho mínimo das espécies para a captura nos rios da Bacia do Paraguai, no Estado de Mato Grosso Sul.

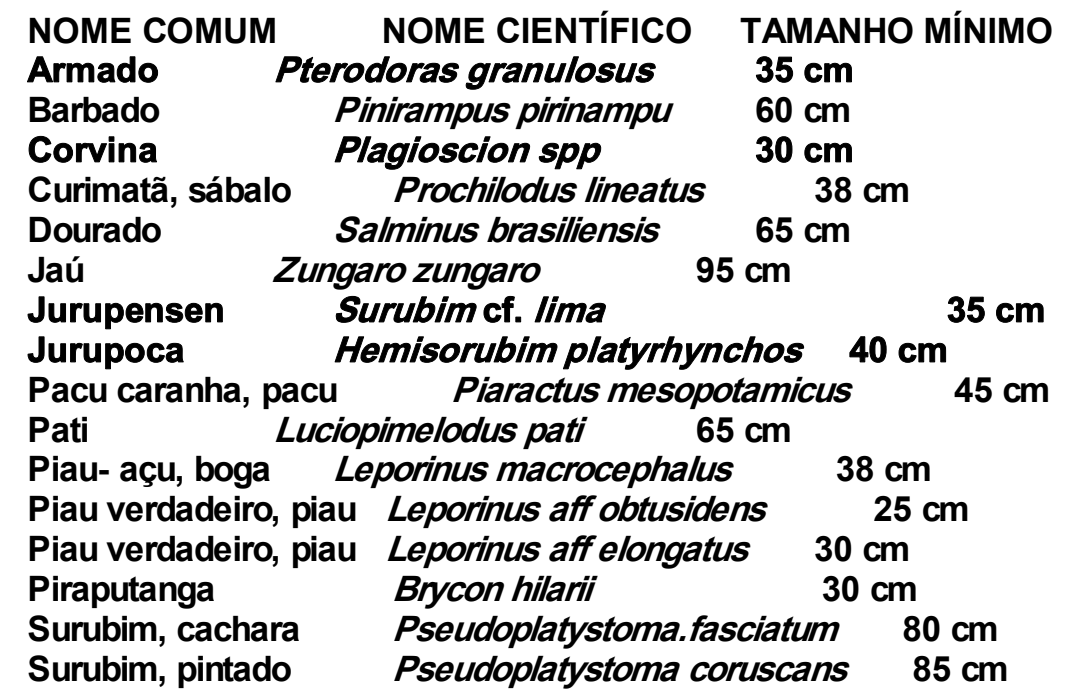


(PORTARIA IBAMA № 3, DE 28 DE FEVEREIRO DE 2008)

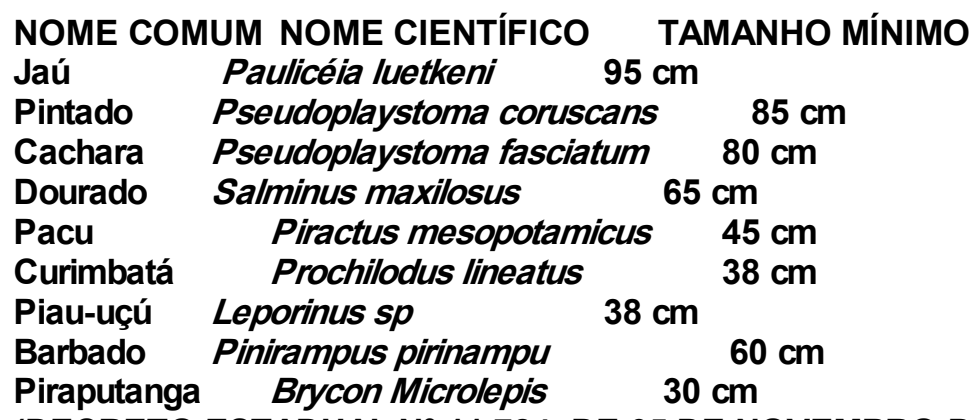

(DECRETO ESTADUAL № 11.724, DE 05 DE NOVEMBRO DE 2004)

Acompanhando as tabelas acima, facilmente se constata que na Portaria do IBAMA existem 04 (quatro) espécies de peixes não tabelados no Decreto Estadual. Isso permite que os pescadores capturem tais espécies em qualquer tamanho, pois a Polícia Militar Ambiental do Estado de Mato Grosso Sul segue apenas o Decreto Estadual, um equívoco danoso para a fauna ictiológica pantaneira.

\section{DO PODER DE POLÍCIA DO ESTADO}

Para dar efetividade às normas ambientais, o poder público utiliza-se do poder de polícia. Com tal prerrogativa, o Estado garante a preservação da ordem pública, limitando o exercício dos direitos individuais em benefício da coletividade.

Maria Sylvia Zanella Di Pietro (2006) aduz que "o fundamento do poder de polícia é o princípio da predominância do interesse público sobre o particular, que dá à Administração posição de supremacia sobre os administrados". (p. 126)

Nesse passo, é através do poder de polícia que os órgãos fiscalizadores ambientais, efetivamente, garantem a tutela do meio ambiente. Esse poder se manifesta através das licenças, permissões, proibições, autorizações e fiscalizações.

Sobre o tema, segue a lição de Toshio Mukai (2004):

O poder de polícia, police power, em sentido amplo, compreende um sistema total de regulamentação interna, pelo qual o Estado busca não só preservar a ordem pública, senão também estabelecer para a vida de relações dos cidadãos aquelas regras de boa conduta e de boa vizinhança que se supõem necessárias para evitar conflitos de direitos e para garantir a cada um o gozo ininterrupto de seu próprio direito, até onde for razoavelmente compatível com o direito dos demais. (p. 89)

Posto isto, denota-se que o poder de polícia possui três funções: preventiva, repressiva e fiscalizadora.

Como analisado, o Pantanal é constituído por rios de interesse da União e dos Estados de Mato Grosso e Mato grosso do Sul. As águas de interesse da União, teoricamente, deveriam ser fiscalizadas por órgãos federais $e$, as de instâncias estaduais, pelos respectivos aparelhos regionais. Todavia, considerando as dificuldades de infra-estrutura, a falta de agentes e principalmente a grande área a ser fiscalizada, sobretudo em território sul-mato-grossense, tal fiscalização, no 
tocante à pesca, é efetuada através de convênio entre o IBAMA e a Polícia Militar Ambiental do Estado de Mato Grosso do Sul.

\section{DELITOS DE PESCA}

A objetividade jurídica dos dispositivos constantes na Lei de Crimes Ambientais, referentes à pesca, está na tutela do equilíbrio ecológico, tendo como sujeito passivo toda a coletividade. Trata-se de crimes formais ${ }^{12}$, salvo melhor juízo, pois o tipo penal não exige a produção do resultado para a consumação do delito, embora seja possível a sua ocorrência.

Transcrevendo os aduzidos dispositivos, in verbis, se tem:

Art. 34. Pescar em período no qual a pesca seja proibida ou em lugares interditados por órgão competente:

Pena - detenção de um ano a três anos ou multa, ou ambas as penas cumulativamente.

Parágrafo único. Incorre nas mesmas penas quem:

I - pesca espécies que devam ser preservadas ou espécimes com tamanhos inferiores aos permitidos;

II - pesca quantidades superiores às permitidas, ou mediante a utilização de aparelhos, petrechos, técnicas e métodos não permitidos;

III - transporta, comercializa, beneficia ou industrializa espécimes provenientes da coleta, apanha e pesca proibidas.

Art. 35. Pescar mediante a utilização de:

I - explosivos ou substâncias que, em contato com a água, produzam efeito semelhante;

II - substâncias tóxicas, ou outro meio proibido pela autoridade competente:

Pena - reclusão de um ano a cinco anos.

Art. 36. Para os efeitos desta Lei, considera-se pesca todo ato tendente a retirar, extrair, coletar, apanhar, apreender ou capturar espécimes dos grupos dos peixes, crustáceos, moluscos e vegetais hidróbios, suscetíveis ou não de aproveitamento econômico, ressalvadas as espécies ameaçadas de extinção, constantes nas listas oficiais da fauna e da flora.

Importa mencionar a admissibilidade do crime tentado, pois a pesca poderia não ocorrer por circunstâncias alheias à vontade do agente.

O núcleo do tipo é pescar e o elemento subjetivo das condutas típicas é o dolo, que consiste na vontade livre e consciente de pescar, utilizando-se dos meios ilícitos ou em desacordo com as normas regulamentares.

\section{CONCLUSÕES}

Especificamente, este trabalho se limitou a apresentar apenas os fundamentos da tutela da ictiofauna pantaneira, discorrendo sobre o art. 225, $\S 3^{\circ}$ da Carta Maior e artigos 34 e 35, da Lei n 9.605/98 (Lei dos Crimes Ambientais).

Tratou-se da competência constitucional em matéria ambiental e de sua repartição entre os entes federados de forma sintetizada. Em termos gerais, foi registrado que tal repartição, segundo posicionamentos doutrinários, deverá obedecer à predominância do interesse, sendo o interesse geral de competência da União, o interesse regional de competência dos Estados membros e o interesse local de competência dos municípios. 
Notou-se que a competência privativa da União não é absoluta, podendo os Estados legislarem em matérias específicas enumeradas pela Constituição, desde que haja Lei complementar nesse sentido.

Observou-se que pertence ao estado-membro o "poder-dever" de editar dispositivos regulamentares, completando as normas penais em branco e disciplinando a proteção da natureza ou a exploração e utilização dos recursos naturais. Exercendo o poder de polícia ambiental, cabe a ele adotar as medidas tendentes a combater a poluição e preservação do meio ambiente. Cabe ressaltar que não há dúvida quanto à constitucionalidade ou à juridicidade das normas estaduais ou municipais que complementem as normas penais em branco ou fundamentem o juízo valorativo dos elementos normativos, desde que tal complementação seja mais benéfica à natureza. Entretanto, não raras vezes, duas ou mais normas, em pleno vigor, podem regulamentar a mesma conduta típica, se apresentando de forma conflituosa.

Assim, para a aplicação da norma ao caso concreto, o aplicador da sanção se recorre aos princípios constitucionais para definir como proceder. Um desses princípios norteadores, como visto, é o da predominância da norma mais restritiva a ação humana. Porém, o mencionado preceito não está sendo lembrado em pleno patrimônio nacional. Tentar-se-á esclarecer tal assertiva com as seguintes considerações:

- O Pantanal é um patrimônio nacional, devendo prevalecer assim, o interesse geral de sua tutela, qual seja, o da União.

- Os Estados Federados não possuem competência legislativa em matéria penal, pertencendo privativamente à União tal competência.

- Sabe-se que a aplicação da conduta criminosa pesqueira depende de normas que regulamentem o tamanho mínimo para a captura, a cota de pescado por pescador, os petrechos, períodos e locais permitidos para a prática da pesca, etc.

-As normas regulamentares do IBAMA são aplicáveis em todo o território nacional, especialmente nos rios de interesse da União (interesse geral).

-As normas da SEMAC são aplicadas no Estado de Mato Grosso do Sul, nos rios de interesse regional.

-Existe, como observado, uma contradição nas tabelas de pescado fixadas para a mesma região (Pantanal sul-mato-grossense) entre o IBAMA e a SEMAC.

Posto isso, pode-se dizer que, ao não compatibilizar suas normas com as Portarias do IBAMA, o Estado de Mato Grosso do Sul está sendo mais permissivo à exploração da pesca. Agindo assim, está consentindo na retirada de espécies que ainda não atingiram o tamanho mínimo para a reprodução, o que pode levar a extinção dessas espécies do bioma pantaneiro, afetando toda a cadeia alimentar dessa fauna.

Portanto, pode-se afirmar que as normas regulamentares estaduais, neste caso, devem acompanhar sistematicamente a legislação federal ou, no mínimo, serem mais restritivas ao homem, pois o Pantanal, como determinado pela constituição, é um Patrimônio Nacional, devendo prevalecer o interesse geral de sua tutela. As normas regulamentares estaduais devem ter eficácia somente nas águas 
de interesse ou competência regional. Assim, a melhor solução para compatibilizar tais normas, de forma que permaneçam em plena harmonia, seria a elaboração de uma Lei Ordinária para a tutela ambiental do Pantanal. Com isso, possivelmente, se dissipariam quaisquer dúvidas sobre a prevalência de interesses, beneficiando a natureza e todos aqueles que contemplam ou exploram os recursos naturais desse "patrimônio mundial".

\section{FISHING CRIMES IN THE PANTANAL: WHOSE IS THE COMPETENCE TO LEGISLATE?}

\section{ABSTRACT}

Based on the Constitutional provisions, this article was intended to investigate the competence of the defense of the Brazilian Pantanal, located in the state of Mato Grosso do Sul. It was found that some constitutional principles are not being obeyed. However, the research did not provide a precise answer to the initial inquiry. As consequence, it was necessary to build na argument based on constitutional hermeneutics, with reference to the current understanding of the matter, achieving a possibility to anwer the question.

Keywords: Blank Criminal Laws. Fishing crimes. Jurisdiction Conflict. Pantanal.

\section{NOTAS}

1 Bacharel em Direito pela Universidade Federal de Mato Grosso do Sul. Pós-graduado em Direito Criminal pela Universidade Católica Dom Bosco (UCDB), Campo Grande/MS (lato sensu) e mestrando bolsista (FUNDECT) em Estudos Fronteiriços pela Universidade Federal de Mato Grosso do Sul. E-mail: fabiomarques2006@ig.com.br.

2 Professor, especialista e advogado. Orientador do Curso de pós-graduação lato sensu da UCDB/ Campo Grande/MS. E-mail: lamartineribeiro@terra.com.br.

3 Graduado em filosofia (FUCMT/MS), Mestre em Educação (UFMS) e Doutor em Educação (UNESP/Marília/SP). Professor e Orientador do Curso de Pós-graduação lato sensu da UCDB/Campo Grande/MS. E-mail: jmanfroi@terra.com.br.

4 Fauna ictiológica: fauna aquática.

5 Período de defeso: época em que os peixes sobem os rios para o ciclo da reprodução (piracema).

6 Sistema Nacional do Meio Ambiente

7 Federalismo: é a união permanente e indissolúvel de Estados autônomos, mas não soberanos, sob a égide de uma Constituição, sendo certo que, entre eles, já há uma repartição interna de atribuições governamentais, sendo-Ihes vedada, porém, a secessão. José Geraldo Brito (FILOMENO, 1997, p. 89)

8 Art. 22, XVII, CF/88: Compete privativamente a União legislar sobre: [...] XVII - organização judiciária, do Ministério Público e da Defensoria Pública do Distrito Federal e dos territórios, bem como organização administrativa destes [...]

9 SEMAC: Secretaria de Estado do Meio Ambiente, das Cidades, do Planejamento, da Ciência e da Tecnologia.

10 IMASUL: Instituto de Meio Ambiente de Mato Grosso do Sul.

11 Embrapa: Empresa Brasileira de Pesquisa Agropecuária (A pesca no Pantanal Sul: Situação atual e Perspectivas, 2004, p. 17).

12 Crimes formais: São aqueles em relação aos quais a lei descreve uma ação e um resultado, mas a redação do dispositivo deixa claro que o crime consuma-se no momento da ação, sendo o resultado mero exaurimento do delito. (GONÇALVES, 2003, p. 10) 


\section{REFERÊNCIAS}

CANOTILHO, José Gomes, MORATO LEITE, José Rubens (org). Direito Constitucional Ambiental Brasileiro. São Paulo: Saraiva, 2007.

CAPEZ, Fernando. Curso de Direito Penal. Vol. 1. São Paulo: Saraiva, 2003.

. Curso de Direito Penal. Vol. 4. São Paulo: Saraiva, 2008.

DI PIETRO, Maria Sylvia Zanella. Direito Administrativo. São Paulo: Atlas, 2006.

FERREIRA, H. S. "Competências Ambientais". Irr. José Gomes, MORATO LEITE, José Rubens (org). Direito Constitucional Ambiental Brasileiro. São Paulo: Saraiva, 2007.

FILOMENO, José Geral Brito. Manual de Teoria Geral do Estado e Ciência Política. Rio de Janeiro: Forense Universitária, 1997.

FRAGOSO, Heleno Cláudio. Lições de direito penal. V. 1. São Paulo: Editora José Bushatsky, 1958.

FREITAS, Vladimir Passos de. A Constituição Federal e a Efetividade das Normas Ambientais. São Paulo: RT, 2005.

GONÇALVES, Victor Eduardo Rios. Direito Penal: Parte Geral. Vol. 7. São Paulo: Saraiva, 2003.

LOBO, P. L. N. Competência Legislativa Concorrente dos Estados-membros na Constituição de 1988. Revista de informação legislativa. Vol. 101. Brasília, Senado Federal, jan.-mar., 1989.

MORAES, Alexandre de. Direito Constitucional. São Paulo: Atlas, 2004.

MUKAl, Toshio. Direito ambiental sistematizado. 4. ed. Rio de Janeiro: Forense Universitária, 2004.

SILVA, José Afonso da. Direito Constitucional Ambiental. São Paulo: Malheiros, 2007.

Recebido para publicação 17/12/2009

Aceito para publicação 30/12/2009 